\title{
Synthetic philosophy
}

\author{
Eric Schliesser ${ }^{1}$
}

Received: 4 November 2018 / Accepted: 11 February 2019 / Published online: 14 March 2019

(c) The Author(s) 2019

\begin{abstract}
In this essay, I discuss Dennett's From Bacteria to Bach and Back: The Evolution of Minds (hereafter From Bacteria) and Godfrey Smith's Other Minds: The Octopus and The Evolution of Intelligent Life (hereafter Other Minds) from a methodological perspective. I show that these both instantiate what I call 'synthetic philosophy.' They are both Darwinian philosophers of science who draw on each other's work (with considerable mutual admiration). In what follows I first elaborate on synthetic philosophy in light of From Bacteria and Other Minds; I also explain my reasons for introducing the term; and I close by looking at the function of Darwinism in contemporary synthetic philosophy.
\end{abstract}

Keywords Synthetic philosophy · Darwinism · Daniel Dennett · Peter GodfreySmith $\cdot$ Professional philosophy $\cdot$ Metaphilosophy

In this essay, I discuss Dennett's From Bacteria to Bach and Back: The Evolution of Minds (hereafter From Bacteria) and Godfrey Smith's Other Minds: The Octopus and The Evolution of Intelligent Life (hereafter Other Minds) from a methodological perspective. I show that these both instantiate what I call 'synthetic philosophy.' They are both Darwinian philosophers of science who draw on each other's work (with considerable mutual admiration). In what follows I first elaborate on synthetic philosophy in light of From Bacteria and Other Minds; I also explain my reasons for introducing the term; I look at the function of Darwinism in contemporary synthetic philosophy; and I close by analyzing the sociological challenges to synthetic philosophy.

By 'synthetic philosophy' I mean a style of philosophy that brings together insights, knowledge, and arguments from the special sciences with the aim to offer a

\footnotetext{
1 The term was coined by Herbert Spencer. His use has a family resemblance to what I propose, but is not exactly the same.
}

Eric Schliesser

nescio2@yahoo.com

1 Political Science, University of Amsterdam, Amsterdam, The Netherlands 
coherent account of complex systems and connect these to a wider culture or other philosophical projects (or both). Synthetic philosophy may, in turn, generate new research in the special sciences, a new science connected to the framework adopted in the synthetic philosophy, or new projects in philosophy. So, one useful way to conceive of synthetic philosophy is to discern in it the construction of a scientific image that may influence the development of the special sciences, philosophy, public policy, or the manifest image. ${ }^{2}$

Dennett and Godfrey Smith are both influential, analytic philosophers. ${ }^{3}$ Even so, I call Dennett's From Bacteria and Godfrey Smith's Other Minds 'synthetic' in order to distinguish their philosophical methods from the analytic philosophy that appears in leading journals.

It is notoriously difficult to define analytic philosophy. But I intend here to evoke the contrast with the kind of decomposition favored by Russell and those influenced by him. Even so, it may be useful to contrast synthetic philosophy with an especially clear way of conceiving a recent strain in analytic philosophy. Daniel Stoljaer's Philosophical Progress: In Defence of a Reasonable Optimism offers a nice presentation of how standards are conceived in some significant parts of contemporary analytic philosophy. The key move is to represent a topic in terms of an argument with plausible premises and an unpalatable conclusion, which, in turn, can be re-conceived as a (say) trilemma. The point of the enterprise-the condition of possibility of progress - then is to find ways to give up one of the plausible seeming premises or find ways to make the conclusion seem less unpalatable.

From Bacteria and Other Minds do nothing of the sort. In particular, both chart "the evolution of the senses, bodies, and behavior. Somewhere in that process lies the evolution of the mind." (Other Minds: 12) The point is then that the reader sees how one could move from mere matter to consciousness by way of discrete steps. ${ }^{4}$ For Godfrey-Smith, this makes sense because for him philosophy is "largely a matter of trying to put things together, trying to get the pieces of very large puzzles to make sense," (12; emphasis in original.) To be sure, Godfrey-Smith recognizes he is doing something that does not seem quite philosophy as ordinarily conceived because he says his book "will move in and out of philosophy." (12) In order to capture this

\footnotetext{
${ }^{2}$ I do not define a complex system, but informally I operationalize it by suggesting it is, in turn, studied by multiple sciences. There also exists a science of complex systems.

3 They are both willing to situate their own project in light of Sellars's distinction between the manifest and scientific image; they are also fond of quoting the first sentence of Philosophy and the Scientific Image of Man, "The aim of philosophy, abstractly formulated, is to understand how things in the broadest possible sense of the term hang together in the broadest possible sense of the term" on Sellar's conception of philosophy. For Godfrey Smith, see his Philosophy of biology. Princeton University Press, 2013, p. 1ff. For Dennet see (inter alia) From Bacteria, pp. 61-63 and also the new preface to Elbow Room: The Varieties of Free Will Worth Wanting (Cambridge: MIT Press, 2015, p. x.)

4 One can discern here the continued influence of Darwin's commitment to Leibniz's principle that nature does not jump (a principle of continuity itself derived from a commitment to the great chain of being). Dennett too rejects single "magic bullets," (so-called sky-hooks) but argues for "a coevolutionary process with lots of contributing factors feeding on each other." (From Bacteria: 149) I return to Godfrey-Smith's point below.
} 
project of immersion in philosophy and the special sciences as well as putting things together, I have re-appropriated 'synthetic philosophy.' 5

One may think that Godfrey-Smith promotes a Kuhnian puzzle-solving image for philosophy. But while he is certainly working within a Darwinian paradigm, Godfrey-Smith is really doing something different than normal science in two ways: first, he is not, in fact, solving micro-puzzles within the paradigm, but rather bringing different elements together to create a coherent whole. The puzzle he is solving is, as it were, at the macro-level. Second, Godfrey-Smith is not doing conceptual analysis, but scientifically informed (naturalistic) philosophy that brings together a wide diversity of scientific findings that cohere-in Godfrey-Smith's case-with his own experience under water. ${ }^{6}$

Dennett's self-understanding also fits how I am conceiving of synthetic philosophy. He writes:

[One may object that:] genes can't explain adaptations (structures, organs, instincts, etc.). That's true; that's why we need molecular biology, physiology, embryology, ethology, island biogeography, and all the other specializations of biology if we are going to explain how particular adaptations work and why they are adaptations. We also need these other fields to explain how parasites exploit their hosts, how spider webs are cost-effective food traps, how beavers build their dams, why whales vocalize, and all the rest. Similarly, [in memetics] we need psychology, anthropology, economics, political science, history, philosophy, and literary theory to explain how and why cultural features (good and bad) work the way they do...Pre-Darwinian natural history at its best was well-developed, systematic science, with hypotheses to test and explanations galore, but Darwin enriched it with a host of questions that put all its generalizations in a new light. My overarching claim in this book is that the evolutionary perspective in general and the memetic perspective with regard to culture transform many of the apparently eternal puzzles of life, that is, meaning and consciousness, in ways inaccessible to those who never look beyond the manifest image that they grew up with and the disciplines they are trained in. (From Bacteria, 242-243.)

Dennett brings Darwinian theory to bear on, and connects existing work in, empirically informed, but still speculative accounts of the origins of mind, language, and life (most of which already deeply influenced by Darwinism) and simultaneously opens up a new meta-science of culture, memetics, that can draw upon and re-orient existing cultural studies and human/social sciences. The focus on (hard to know) origins is not just a sly tactic to avoid empirical refutation, but it is the

\footnotetext{
5 Analytic philosophy, as conceived by Stoljaer, and synthetic philosophy are, in principle, sometimes compatible with each other in so far as synthetic philosophy can be taken to provide empirical support for (or undermine) the premises and/or the (purportedly) unpalatable conclusion of some arguments.

${ }^{6}$ In his earlier Philosophy of biology, Godfrey-Smith understands his philosophy of nature as focused on "how everything hangs together" and drawing on science to "put together an overall picture of the world," (emphasis in original, Op. cit, 2013, p. 4.) I thank Trevor Pearce for reminding me of this text.
} 
application of Darwin's own claim that "all true classification is genealogical; that community of descent is the hidden bond which naturalists have been unconsciously seeking," (Chapter 13, The Origin of Species.) ${ }^{7}$

Synthetic philosophy, which shares kinship with what was once known as "natural philosophy' or (later) 'philosophy of nature' 8 is made possible by, and a response to, the intellectual division of labor within and among the scientific disciplines. It requires skills that are orthogonal to the increasing specialization within the increasingly esoteric sciences. It is, thus, a modern phenomenon of the last two centuries. Of course, it is not the only possible philosophical response to such specialization; for example, Neurath's conception of orchestration and the development of a unified, scientific language was an alternative approach. ${ }^{9}$

Synthetic philosophy can be understood as the generation (and stabilization) of a scientific image out of disparate, esoteric special sciences. Because both From Bacteria and Other Minds are directed at a wider audience (they are simultaneously an instance of public philosophy), it is no surprise that their works bear on the relationship of the scientific image with the manifest image. And so they instantiate a characteristic function of synthetic philosophy: being a vehicle for the dynamic interaction and co-evolution of the manifest and scientific images. So, for Dennett, both the scientific and manifest images are real patterns. But from the perspective of the scientific image, the manifest image of each species is "a user-illusion brilliantly designed by evolution to fit the needs of its users."10

Dennett's late work, From Bacteria, brings his views in the philosophy of mind and philosophy of biology together, yet brims with new ideas. ${ }^{11}$ A key one is the notion of free-floating rationales, which are a species of reasons, "tracked" by "evolution" (50). In context Dennett is describing "the accumulation of function by a process that blindly tracks reasons, creating things that have purposes but don't need to know them." (49) So, free-floating rationales are reasons that do not require being

\footnotetext{
7 As Dennett himself admits (see, e.g., 149 and 281), From Bacteria is a list of as-of-yet unsolved problems. There is an irony lurking here; in the philosophy of mind, Dennett is known for being quite critical of the "mysterians" (373; that is, Searle, Chomsky, etc.) and the folk who embrace variants of the explanatory gap (p. 20; e.g., Levine) or the hard problem (p. 318, Chalmers, etc.). In a way, his main criticism of these approaches is not that they give up too early or too easily (although surely he believes that as well, or that they have underappreciated how much he has done toward explaining consciousness), but rather that the difficulty of the problem of consciousness is, in fact, under-appreciated because it involves not the characterization and location of some dividing line, but rather many multi-dimensional problems about how our embodied and (linguistically and materially) encultured competences-many, but not all, without comprehension-hang together in various not-so-seem-less (even if the gaps are often obscure to the first person) ways. And despite the famous title of Dennett 1991, at best Dennett has sketched the contours of a possible explanation by telling a plausible origin story with discrete steps and the evolution of competences as well as relating our kinds to other kinds of minds.

${ }^{8}$ Godfrey-Smith (2013) op. cit., p. 4. There are also resonances with speculative philosophy and systematic philosophy.

9 Neurath, Otto. "The orchestration of the sciences by the encyclopedism of logical empiricism." Philosophy and Phenomenological Research 6.4 (1946): 496-508.

10 On my view a recurring pattern of such speech acts ends up influencing features of the manifest image and so there may be coalescence between them. I thank Enoch Lambert for discussion.

11 And changes of mind.
} 
represented for their existence: in particular, they are functions that are a consequence of natural selection. (One way to understand a free-floating rationale is that it is the answer to the why question of reverse engineering. (92))

For Dennett free-floating rationales are not merely a biological phenomenon; he also treats cultural evolution as the cause of particular types of free-floating rationales: "memes, informational viruses that govern infectious habits," (173, emphasis in original.) Now, Dennett is primarily interested in explaining consciousness and the origins and the nature of language, but he also wants to show that "Free-floating rationales have been as ubiquitous in cultural evolution as in genetic evolution." (231)

In particular, Dennett's free-floating rationales are also a means to make talk of functions in the social science and a new science of culture respectable again (211-212). Social functions simply are flee-floating rationales that are caused by cultural evolution (and, perhaps, biological evolution). These can but need not be represented by agents in society. Of course, showing that an attributed social function is the consequence of such cultural selection is not always easy (but that's for another time). Free-floating rationales are an example of the way Dennett's Darwinian synthetic philosophy both draws from and aims to redirect different special sciences.

As noted, Darwinism provides the synthesizing glue for From Bacteria and Other Minds. The Darwinian spirit is exemplified by Godfrey-Smith's claim, that "Good philosophy is opportunistic; it uses whatever information and whatever tools look useful." (12) The commitment to Darwinism is no coincidence because Darwin himself is the hard-to-classify (among the) last natural philosopher(s)/naturalists or (among) the first synthetic philosopher(s). Darwin had brought together insights from a whole number of distinct sciences (geology, botany, paleontology, morphology, entomology, animal husbandry, climate science, etc.) and, in turn, self-consciously revolutionized them with his ideas and opening up new avenues for scientific research.

Dennett's attitude toward those special sciences and humanities, which have not yet adopted memetic theories of cultural evolution, is akin to (and explicitly modeled on) Darwin's attitude toward the pre-Darwinian special sciences. They are useful as sources of evidence because they have not yet been contaminated by his theory (238-239).

Dennett draws on some of Darwin's own examples or very cleverly recasts them. For example, Darwin deploys a trope from Mandeville and Hume in which the slowly evolved complexity of a ship stands for the unintended functionality of bottom up effectiveness of the division of labor; this example is both re-used (214, drawing on anthropological evidence that acknowledges Darwin) and recast by Dennett in an extended analysis of Leslie Groves top-down design of the Manhattan Project, which involved thousands of competent workers who had no comprehension of what they were contributing to (69-72).

Dennett's From Bacteria is packed with scientific evidence, thought experiments, and rich analogies and other tools for thought. By contrast, Other Minds, while equally wide ranging, has a sparse elegance. It has that rare quality of articulating features of reality that seem obvious once stated (my favorite: the "dual role" of 
light as a source of energy and a source of information), but that may have eluded recognition before reading it. Other Minds is a masterful introduction to three different topics: octopus and squid cognition; human cognition; and modern understanding of evolution by natural selection. ${ }^{12}$ A key insight that runs through the book is that there are two kinds of internalization: "the nervous system arose through one internalization of sensing and signaling, and the internalization of language as a tool for thinking was another. In both cases, a means of communication between organisms became a means of communication within them." (Other Minds: 153)

Other Minds has an epigraph from William James:

The demand for continuity has, over large tracts of science, proved itself to possess true prophetic power. We ought therefore ourselves sincerely to try every possible mode of conceiving the dawn of consciousness so that it may not appear equivalent to the irruption into the universe of a new nature, nonexistent until then.-William James The Principles of Psychology, 1890

Godfrey-Smith interprets James as saying that "we need a theory [of consciousness] based on continuities and comprehensible transitions; no sudden entrances or jumps." (11) That is, Godfrey-Smith sees James as agreeing with Darwin's demand that nature does not jump.

But Godfrey-Smith may also have something further in mind, "like James, I want to understand the relationship between mind and matter, and assume a story of gradualism is the story that has to be told." (11) Godfrey-Smith's narrative is one of deep time, a longue durée, where many of the key moves take places hundreds of millions of years ago and accumulate slowly over time. ${ }^{13}$ While the story told in Other Minds is, in principle compatible with the Baldwin effect and other evolutionary cranes that accelerate evolution, on the whole he is not much interested in such moves (that connect human intelligence to environmental pressures and learned evolution).

James is explicitly echoing Leibniz's principle of continuity. ${ }^{14}$ This is, in fact, a Platonic principle (creatively re-interpreted by Leibniz) that in the nineteenth

\footnotetext{
12 Below the surface, as it were, there is a whole treatise on how developing sciences work: we hear, en passant, about scientists switching research topics and withholding papers from each other until publication; we learn about prestige hierarchy in science and how the significance of neglected papers can be discovered much later; the non-trivial role of non-scientists in marine biology; the ways in which background theory informs interpretations of experiments, and the ways philosophers can be constructive participants in science, etc.

13 Other Minds is a kind of indirect response to Thomas Nagel's Mind and Cosmos. (Nagel is mentioned in Other Minds but not that book.) For it shows that complex intelligence evolved multiple times from many intersecting mechanisms in evolutionary history along different branches and with at least two very distinct Baupläne. It shows that within a broadly scientific framework one can, in fact, say quite a bit about the nature of consciousness (rather than being hampered by the so-called Absolute Conception, which entails that the very success that science may have had is intrinsically tied to subtracting mind from nature).

14 "Nothing takes place suddenly, and it is one of my great and best confirmed maxims that nature never makes leaps." (A VI vi 56/RB 56) More exactly, Leibniz believes that this law or principle implies that any change passes through some intermediate change and that there is an actual infinity in things. The Principle of Continuity will be employed to show that no motion can arise from a state of complete rest and that "noticeable perceptions arise by degrees from ones which are too minute to be noticed." (ibid.) quoted from, Look, Brandon C., "Gottfried Wilhelm Leibniz", The Stanford Encyclopedia of Philosophy (Summer 2017 Edition), Edward N. Zalta (ed.), https://plato.stanford.edu/entries/leibniz/\#PriCont.
} 
century got reinterpreted, in turn, to imply that every possible species niche would be occupied. It is an image of boundless (even infinite) nature with endless possibility. I doubt that this is Godfrey-Smith's image of nature, but since he treats the body of the octopus "as pure possibility," it's clear he is also tempted by it.

I do not want to give an impression that synthetic philosophy is a recent phenomenon. Darwinian synthetic philosophy of mind and philosophy of science has had a good run during the last four decades. ${ }^{15}$ And there are other, earlier works, that would qualify as synthetic philosophy drawing on Darwinian theory. For example, Rachel Carson's (1962) Silent Spring - it helped found the modern environmental movement-draws on an amazing number of different sciences (not just physics, chemistry, biochemistry, genetics, and medicine, but also entomology, botany, ecology, zoology, crop-management, forestry, fisheries, oceanography, etc.) and integrates these with issues in public health and public policy. ${ }^{16}$

What's crucial for my present purposes is that Carson uses Darwinian style reasoning throughout the work and an ecological interpretation of Darwin's theory integrates the many strands of the argument. ${ }^{17}$ The key point, and this runs through the book, is that many well-intended large-scale interventions generate unintended and often counterproductive consequences. She thinks these consequences are often foreseeable to informed bystanders if one were willing to leave one's intellectual silo or think through the ecological situation. ${ }^{18}$ That is, a certain kind of generalistthe synthetic philosopher-may well foresee outcomes that the specialist is trained to ignore. ${ }^{19}$ The synthetic philosopher can call attention to a wide array of strategies and consequences that cut across specializations. More important, she can draw attention to the wider salience of a phenomenon that a specialist may miss. That is, while speculation and informed guesses cannot be avoided in synthetic philosophy, it can also produce a species of understanding (recall Other Minds quoted above) that is if not knowledge, at least distinct from the parts from which it is composed.

Furthermore, I do not mean to suggest that synthetic philosophy must draw on Darwinism. Synthetic philosophy requires a general theory such as game theory or information theory (and perhaps Bayes' theorem) that is thin and flexible enough to

\footnotetext{
15 Hull, David L. Science as a process: an evolutionary account of the social and conceptual development of science. University of Chicago Press, 1988; Sterelny, Kim. Thought in a Hostile World: The Evolution of Human Cognition. (2003), Oxford: Wiley-Blackwell.

${ }^{16}$ Carson, Rachel. Silent Spring. Houghton Mifflin Harcourt, 1962. She also anticipates discussions of inductive risk, the use of precautionary principles, the (statistical) interaction of what are taken to be isolated effects/phenomena, the use of natural experiments, the problem of scaling up results obtained in the laboratory, the problems of bias (in sponsored research), and the role of rent-seeking in government, etc.

17 I do not mean to suggest that Carson is only or best understood as a synthetic philosopher (her work makes no effort to insert itself in the history of philosophy). But Silent Spring very nicely instantiates the kind. It's also filled with arguments.

18 This is a key feature of Adam Smith's use of 'invisible hand,' see Eric Schliesser (2017) Adam Smith: Systematic Philosopher. Oxford: Oxford University Press, pp. 250-250.

${ }^{19}$ I am not claiming that only a synthetic philosopher can foresee such outcomes. Carson herself drew on a whole range of supportive, scientific informers. In addition, it is quite possible the chemical companies she criticizes were aware of the dangerous effects they created.
} 
be applied in different special sciences, but rich enough that, when applied, it allows for connection to be developed among them.

In conclusion, I address two related, questions: first, how does one judge the merits of synthetic philosophy? Second, how is synthetic philosophy possible in the contemporary intellectual landscape? While the former question is primarily epistemic and evidential and the latter primarily sociological, it would be naive to consider them entirely separately. For, it is, of course, no coincidence that my main examples of synthetic philosophy are books written by senior scholars (Dennett, Godfrey-Smith), a political activist (Carson), and a gentleman-scholar (Darwin), and that these books are aimed, in part, at a wider intellectual audience. In addition, given the reality of specialization, even within academic philosophy, and given the expectations of tenure (for which journal publications are often key), one may well wonder how synthetic philosophy is possible for those coming up in the ranks.

But, first, I turn to the criteria of evaluation of synthetic philosophy. These need not be invented out of whole cloth. For, some of the ordinary criteria of naturalistic philosophy - sound argument, careful evaluation of evidence, knowledge of the sciences, etc.-carry over without problems. In addition, synthetic philosophies can be evaluated in light of traditional theoretical virtues. In particular, the following virtues are especially relevant: unification, scope, applicability, and fertility or fruitfulness. ${ }^{20}$ Unification and scope refer to the way in which synthetic philosophy develops a coherent and integrated account of disparate elements supplied by the special sciences. By applicability I refer to the ways in which synthetic philosophy can be applied to existing problems in the special sciences, philosophy, or public policy. With fertility I mean to call attention to the role of synthetic philosophy of generating new cognitive tools and solutions to be used in the special sciences ${ }^{21}$ and philosophical reflection (including the development of useful new myths). ${ }^{22}$ The development of new cognitive tools (concepts, distinctions, formal methods, theoretical extensions, etc.) for the special sciences and philosophy is an especially important feature of synthetic philosophy.

This is so because in addition to providing a general kind of understanding, creating cognitive tools for the special sciences (and philosophy or public policy, etc.) is a distinctive feature of synthetic philosophy. Synthetic philosophy is meant to be

\footnotetext{
${ }^{20}$ For a list of twelve such virtues-evidential accuracy, causal adequacy, explanatory depth, internal consistency, internal coherence, universal coherence, beauty, simplicity, unification, durability, fruitfulness, and applicability—see Keas, Michael N. "Systematizing the theoretical virtues." Synthese 195.6 (2018): 2761-2793.

21 For an independent defense and model that justifies this claim, see De Langhe, Rogier, and Eric Schliesser. "Evaluating Philosophy as Exploratory Research." Metaphilosophy 48.3 (2017): 227-244.

22 The point about myth may come out of the blue-but Dennett writes (a) "The work on reason-giving and normativity descended from Sellars at Pittsburgh, via Brandom, McDowell, and Haugeland, has never stressed, to my knowledge, that these all-important human practices are systematic generators of false ideology whenever the demand for reasons exceeds the available supply" (314 n. 97) and (b) "[B]y shielding your precious experience from probing, you perpetuate myths that have outlived their utility." (351) This suggests Dennett thinks there may be true ideology and, more plausibly, some myths that are useful.
} 
generative of other intellectual (scientific, etc.) projects. Dennett ${ }^{23}$ and Godfrey$\mathrm{Smith}^{24}$ are exemplars of this very practice.

This last point can help address part of the sociological challenge, which is real. There are many obstacles to becoming a synthetic philosopher: one must be a skilled amateur in many sciences and have the capacity to synthesize a lot of technical information in a demanding theoretical framework. In addition, there are currently no lines for would-be-synthetic philosophers in philosophy departments. Luckily, many universities are promoting interdisciplinary centers where philosophers that can engage with multiple sciences can find a home. At first synthetic philosophers will be hired as philosophers of science, philosophers of mind, biology, etc. And even if philosophy journals are not always welcoming to synthetic philosophy, there are outlets for (speculative) contributions to the sciences in scientific journals. ${ }^{25}$

In conclusion, philosophers often enjoy telling a story about the history of philosophy in which philosophy functions as an incubator of the sciences. The way I understand synthetic philosophy that function remains part of our future. But that's not all: the sciences are also the incubators of synthetic philosophy.

Acknowledgements I thank Daniel Dennett, Bryce Huebner, Enoch Lambert, Trevor Pearce, Charles Wolfe, Martin Lenz, and Michael Weisberg for comments on earlier drafts of this paper. The usual caveats apply.

Open Access This article is distributed under the terms of the Creative Commons Attribution 4.0 International License (http://creativecommons.org/licenses/by/4.0/), which permits unrestricted use, distribution, and reproduction in any medium, provided you give appropriate credit to the original author(s) and the source, provide a link to the Creative Commons license, and indicate if changes were made.

Publisher's Note Springer Nature remains neutral with regard to jurisdictional claims in published maps and institutional affiliations.

\footnotetext{
${ }^{23}$ Recall Dennett's aim to contribute to a renewed "science of culture" (From Bacteria 211-212).

24 Based on his research, Godfrey-Smith ended up writing a scientific paper on the "function of the nervous systems and their early evolution" (Other Minds: 210, n. 23).

25 This raises complicated challenges about evaluating tenure files of would be synthetic philosophers.
} 